\title{
Timor-Leste: Investimento para todos
}

\section{East Timor: Investment for all}

\section{Agio Pereira ${ }^{1}$}

\footnotetext{
${ }^{1}$ Ministro de Estado e da Presidência do Conselho de Ministros do VI Governo Constitucional de Timor-Leste E-mail: agiopereira@gmail.com
}

\begin{abstract}
Resumo
País acolhedor por tradição e naturalmente rico e diversificado, dotado de um plano de desenvolvimento sustentado com horizonte em 2030. Timor-Leste mostra-se aberto e desejoso por receber investidores nacionais e estrangeiros de diversos setores, desde a agricultura ao turismo, passando por diversas indústrias e por serviços vários, apoiando pequenos, médios e grandes investimentos. Tendo sido consolidada a paz e edificado o quadro legal fundamental para a estabilidade democrática, o espaço económico timorense revela agora as suas oportunidades para investimento em projetos que apoiem 0 desenvolvimento e o emprego.
\end{abstract}

Palavras-chave: Investimento; economia; desenvolvimento; oportunidades; educação; cultura.

\begin{abstract}
Traditionally, a welcoming country with a rich and diversified nature, East Timor has a sustained plan of development to be accomplished until 2030. It is looking forward to receive national and international investors from every services and industrial sectors, like agriculture and tourism, supporting all types of investments. Since piece has been declared, as well as the legal board of democracy has been edified, the economical space of Timor is now revealing his own opportunities to invest in projects that will sustain the development of employment.
\end{abstract}

Keywords: Investment; economy; development; opportunities; education; culture. 


\section{Enquadramento geral}

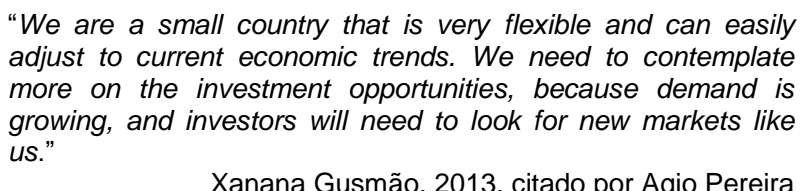

Xanana Gusmão, 2013, citado por Agio Pereira

A grande vantagem para os investidores num dos mais jovens e perseverantes países do mundo - Timor-Leste - reside, paradoxalmente, no facto de a economia estar num estádio inicial, com os meios de produção ainda em grande parte centrados no Estado. Resolvidas as questões mais urgentes, em termos de organização política, social e económica, considera-se chegado o momento de incentivar o investimento privado, como forma de garantir diversificação e reconhecimento nacional, visando o bem-estar sustentável da população.

Partindo de um cenário de total devastação, em 1999, após a retirada do ocupante indonésio, os timorenses, com apoio de organizações internacionais, reconstruíram a economia da sua sobrevivência. A saída das forças das Nações Unidas de apoio à reconstrução nacional (UNTAET), em 2012, colocou Timor-Leste numa nova etapa do seu crescimento.

A maturidade do país havia ficado já bem clara com a aprovação do Plano Estratégico de Desenvolvimento 2011-2030, que traça metas claras para a atuação dos futuros governos, apontando para todos eles uma visão de futuro. As raízes lançadas nos anos após a lição de determinação do povo timorense, que resultou na devolução da independência em 2002, permitem hoje encarar uma nova etapa para a economia nacional, aberta à privatização dos diversos setores de negócio.

O Estado continua apostando em construir um edifício legal, moldado na produção das grandes organizações internacionais - convenções e outros tratados multilaterais -, em dotar o país de boas infraestruturas, em manter um clima de paz sustentado, em assegurar condições de saúde e em criar um projeto educativo de promoção cultural. Deste modo, assegurará também uma boa qualidade de vida ao povo, através de factores de desenvolvimento com futuro garantido.

Os dados estatísticos estão sempre desfasados da realidade, mas uma coisa é incontestável: Timor-Leste tem vindo a mostrar um crescimento constante, sustentado em todos os vetores da vida económica e social. Entra-se agora na fase de diversificação económica e de promoção da atividade do setor privado, nacional e estrangeiro, como tónica do crescimento da produção interna, com benefícios para o conjunto da população.

\section{Condições físicas}

Timor-Leste ocupa a parte oriental da ilha de Timor, situada na confluência dos oceanos Índico e Pacífico. Vizinho próximo da Austrália e da Indonésia, o país situa-se numa encruzilhada de rotas marítimas, que continuam a ditar a movimentação da grande maioria das produções do sudeste asiático para o oeste, a caminho da Europa e, dos bens que circulam em sentido contrário, rumo à China e às economias da costa americana do Pacífico. De Timor-Leste, fazem parte também o enclave de Oe-Cusse Ambeno e as ilhas de Ataúro e Jaco.

A sua proximidade face à linha do Equador dita-Ihe um clima quente e, de certo modo, húmido. Com uma orografia, fundamentalmente, demarcada por montanhas de alto relevo, ao solo é lhe garantido todos os benefícios de chuvas abundantes. Contudo, tratando-se um território bastante pequeno, os acasos do relevo proporcionam zonas de microclima que, por sua vez, promovem uma grande diversificação de culturas.

Os 706 quilómetros de costa delimitam uma zona de exclusividade marítima, com águas de temperaturas elevadas, que abrigam recifes de corais considerados como dos mais bem preservados do mundo, ultrapassados apenas em variedade de espécies pela vizinha PapuaNova Guiné. Neste momento, estão já definidos 573 quilómetros quadrados de área marítima 
protegida, sobretudo na zona de confluência interoceânica, na ponta leste da ilha ${ }^{1}$. O relatório de 2008 da Timorese Reef Check revelou não haver danos antropogénicos, nem lixiviação ou doenças nos corais analisados. Entendido como um ecossistema delicado, o recife de coral é, não só, o berçário de um grande número de espécies que irão povoar os oceanos vizinhos, mas também o viveiro natural de peixes de grande interesse alimentar e comercial imediato.

\section{Condições políticas}

Timor-Leste vive num clima de paz estável, governado por uma democracia parlamentar e constitucional. Com a retirada das forças das Nações Unidas, os maiores partidos eleitorais assumiram o controlo conjunto de ocasionais focos de tensão política, resolvidos sem agitação popular ou intervenção das forças da ordem. Estas têm estado particularmente vocacionadas para a formação interna, apoiada por países cooperantes, em diversas frentes. Saliente-se a vocação dessas forças para o apoio à Proteção Civil e para o cumprimento dos compromissos de adesão a tratados internacionais, como os de prevenção e combate ao tráfico de estupefacientes e de seres humanos, de vigilância das águas territoriais ou de coordenação militar na região do Sudeste Asiático.

A Constituição garante a separação de poderes entre órgãos de soberania, onde o quadro legal tem sido constantemente enriquecido e posto em prática com grande independência pelos magistrados. $O$ acesso aos tribunais está garantido a todos os que dele pensem necessitar. A par do edifício jurídico e judicial, estão a ser formadas novas gerações de juízes timorenses, que irão melhorar a capacidade de resposta e a eficácia do sistema já montado.

O sistema jurídico segue genericamente o perfil da Civil Law (tradição romano-germânica), com as adaptações consideradas necessárias à realidade local, sendo de registar a importante tentativa de manter espaço para práticas ancestrais de resolução de conflitos pelos anciãos nas suas comunidades, espalhadas pelo país. A evolução do quadro legal acompanha os desafios colocados ao país, nomeadamente no domínio económico, com vista a tornar mais rápidos e transparentes os procedimentos administrativos nessa área.

A segurança interna está a cargo da Polícia Nacional de Timor-Leste, que tem passado por processos intensivos de formação técnica em todas as áreas, desde a Polícia Científica às Brigadas de Trânsito. Procura-se manter o baixo índice de criminalidade e de violência, tarefa deveras facilitada pela inexistência de crime organizado.

De uma maneira geral, há praticamente uma década que a vida em Timor-Leste é pacífica, registando-se apenas episódios dispersos de pequenos crimes, que tendem a surgir em zonas de maior concentração urbana. Estes apresentam um índice positivo, com um decréscimo de $20 \%$ de ocorrências, no período de 2010 a $2015^{2}$. As medidas de curto prazo para o desenvolvimento do país têm vindo a ser alcançadas e o rumo traçado, com horizonte em 2030. Tal facto aumenta a confiança da população residente e estrangeira sobre o que esperar da pequena grande nação que é Timor-Leste.

\section{Condições sociais}

A rápida melhoria e sustentabilidade das condições de vida da população de Timor-Leste são a maior preocupação das políticas governamentais. Os grandes esforços legislativos e económicos vão todos no sentido de garantir o bem-estar, a saúde, a educação e a habitação da população em geral. A medida política mais importante entretanto posta em prática no país, o Plano Estratégico de Desenvolvimento (PED), traça as metas governamentais até 2030, conforme os Objetivos de Desenvolvimento Sustentável das Nações Unidas.

\footnotetext{
${ }^{1}$ Cf. http://www.protectedplanet.net/country/TL, da World Database on Protected Areas (WDPA) - consultado a 20 de maio de 2016.

2 Dados estatísticos facultados pela Polícia Nacional de Timor-Leste.

E3 - Revista de Economia, Empresas e Empreendedores na CPLP | Volume 3 | Número 1
} 
Em causa estão as vidas de 1,16 milhões de pessoas, contabilizadas no Censo de 2015 - um acréscimo populacional de $9,4 \%$ relativamente a 2010 -, cerca de metade das quais entre os 15 e os 54 anos de idade. Consequência significativa resultante dos esforços desenvolvidos nos anos da independência. A esperança média de vida dos timorenses passou de 58 anos de idade, em 2003, para 62 anos, em 201033, e para 66 anos, em $2015^{4}$.

\section{Saúde}

As políticas de abordagem dos problemas de saúde têm atuado em todas as áreas em simultâneo, na sua maioria, com resultados muito animadores. Em termos de pessoal clínico, passou-se de 0,9 médicos por cada 10.000 habitantes, em 2012, para 7,3, em 2015. No que diz respeito ao pessoal de enfermagem, os valores são de 1,6 para 3,5, no mesmo período.

O trabalho de formação começa a dar frutos. Inicialmente, o pessoal médico assentava quase integralmente na ajuda internacional, do qual se destaca a intensa cooperação de Cuba. Hoje, o país conta com técnicos de enfermagem e médicos de clínica geral timorenses, formados no estrangeiro e, agora também, com estudos iniciados na Universidade Nacional de Timor Lorosa'e.

A assistência de proximidade tem sido uma preocupação e a pequena rede hospitalar (5 hospitais públicos) é complementada por 69 Centros de Saúde e Postos de Saúde, fixos e ambulatórios, que dão assistência até mesmo às populações rurais residentes em zonas remotas, passando de 216 postos, em 2012, para 256, em 2015.

Com o apoio de técnicos internacionais, Timor-Leste montou o seu Sistema Integrado de Saúde (SISCa), que coordena programas em vários setores. O Programa Saúde na Família, testado ao longo de vários anos na capital, foi alargado a todo o país e pretende chegar, até ao final de 2016, a todas as famílias das 2.225 aldeias de Timor-Leste, que passam assim a ser visitadas e acompanhadas regularmente pelos profissionais de saúde, para tratamento, prevenção e informação.

A distribuição de medicamentos é gratuita em todas as prescrições da rede pública nacional. Com todas as limitações ainda reconhecíveis, os resultados são claros. Timor-Leste foi um dos 9 países do mundo que cumpriu a meta 5 dos Objetivos de Desenvolvimento Sustentável em matéria de redução da taxa de mortalidade materna, com um decréscimo superior a $75 \%$, desde 1990. Das 557 mortes por 100.000 partos, ainda em 2010, passou-se para 270, em $2015^{5}$. Para tal, muito contribuiu o aumento da assistência médica nos partos por pessoal qualificado - passaram de 29,6\%, em 2010, para $60 \%$, em $2015^{6}$. Também os cuidados pré natais passaram de $67,9 \%$, em 2009 , para $75 \%$, em $2015^{7}$.

As campanhas de vacinação e o acompanhamento dos técnicos de saúde em matéria de conselhos de higiene e de prevenção têm obtido resultados notáveis, traduzindo-se no recuo dos valores da mortalidade infantil $(88 / 1000 \text {, em 2003; 48/1000, em 2015) })^{8}$ e da taxa bruta de mortalidade $(6,5 / 1000$, em 2002; 6,1/1000, em 2014) .

O Programa Nacional de Controle da Malária mereceu o prémio da Organização Mundial de Saúde para a Região do Sudeste Asiático, em 2014. A campanha nacional de imunização contra o sarampo, rubéola e poliomielite de 2015 chegou a 93\% das crianças com idade inferior a 15 anos.

\footnotetext{
3 Dados do "Demographic and Health Survey" (DHS) do Instituto de Estatística, "2000-2015: Perfis de Saúde de TimorLeste - Progressos", apresentados em 2016.

${ }^{4}$ Dados do "World Health Report" (WHR) da Organização Mundial de Saúde. Os do DHS serão publicados em 2016.

${ }^{5}$ Dados de Saúde apresentados na GMPTL Conference de 2016, intervenção da Ministra da Saúde.

${ }^{6}$ Ibid.

${ }^{7}$ Ibid.

8 Ibid.

${ }^{9} \mathrm{CIA}$, World Fact Book, https://www.cia.gov/library/publications/the-world-factbook/geos/tt.html , consultado em 20 de maio de 2016.

E3 - Revista de Economia, Empresas e Empreendedores na CPLP | Volume 3 | Número 1
} 
Alguns dados sobre evolução da Saúde em Timor-Leste:

\begin{tabular}{|l|l|l|}
\hline Esperança média de vida à nascença & $2010-62$ anos & $2015-66$ anos \\
\hline $\begin{array}{l}\text { Taxa de mortalidade abaixo dos 5 } \\
\text { anos }\end{array}$ & $2003-125 / 1000$ & $2015-57 / 1000$ \\
\hline Malnutrição abaixo dos 5 anos & $2010-52 \%$ & $2015-45 \%$ \\
\hline Incidência de malária & $2003-400 / 100.000$ & $2015-8 / 100.000$ \\
\hline
\end{tabular}

Fonte: Dados de Saúde apresentados na GMPTL Conference de 2016, intervenção da Ministra da Saúde.

Enquanto houver uma morte evitável, nenhum Governo pode dar-se por satisfeito. Timor-Leste sabe apenas que está no bom caminho para aproveitar ao máximo os seus próprios recursos e os apoios internacionais. E é com prazer que se assiste hoje a investimentos privados nesta vertente, o que vem colmatar as fragilidades existentes em áreas técnicas que ainda não foram devidamente cobertas pela rede pública, quer pelos valores de investimento envolvidos, quer pelas exigências técnicas a nível de operação e manutenção de equipamentos.

\section{Educação}

A educação é outro setor em que se tem procurado obter resultados significativamente superiores. A situação herdada em 2002 era calamitosa, sendo que $60 \%$ da população adulta era iletrada e grande parte dos professores era da Indonésia. Hoje, a economia mundial exige empregar mão-de-obra com habilitações mínimas, ou seja, pelo menos capaz em termos de literacia e numeracia. Aguarda-se o resultado do Levantamento de Dados sobre Recursos Humanos em Timor-Leste, um censo exaustivo especificamente focado nas competências do potencial humano timorense. Os dados deverão estar disponíveis no início de 2017, permitindo que se tomem então medidas para desbloquear a rápida valorização técnica e literária dos timorenses em idade ativa.

Dos resultados dos censos publicados, verifica-se que, de 2004 para 2010, os esforços públicos mais do que duplicaram o número de alunos nos níveis primário e secundário, abrangendo $80 \%$ da população infanto-juvenil. As indicações existentes são de que se continuou a avançar na inclusão de um maior número de jovens, estabilizando, assim, a taxa de abandono escolar por volta dos $3 \%$.

\begin{tabular}{|l|l|l|l|l|l|l|}
\hline \multicolumn{3}{|l|}{ Nível de escolarização da população com mais de 3 anos de idade em 2015 } & $\begin{array}{l}\text { Não } \\
\text { formal }\end{array}$ \\
\hline $\begin{array}{l}\text { Pré- } \\
\text { Primário }\end{array}$ & Primário & $\begin{array}{l}\text { Pré- } \\
\text { Secundário }\end{array}$ & Secundário & $\begin{array}{l}\text { Politécnico/ } \\
\text { Vocacional }\end{array}$ & Universidade & \\
\hline 50.048 & 316.062 & 132.186 & 165.931 & 7.604 & 68.758 & 8.141 \\
\hline
\end{tabular}

Fonte: Instituto de Estatística, Dados do Censo de 2015

Tem-se procedido a um grande esforço de recuperação e alargamento do parque escolar - na última década, foram construídas ou recuperadas mais de 2.000 escolas por todo o país, sendo que 830 foram construídas desde $2012^{10}$. É também muito importante o investimento na formação e na reciclagem de professores, bem como a sistematização de currículos, adaptando-os às atuais necessidades do mundo de trabalho. Com o apoio da cooperação portuguesa, está em campo uma rede de Centros de Apoio à Formação de Professores (CAFE), que abrange todos os Municípios, através da formação de professores timorenses "on the job", pondo em prática metodologias de ensino diferentes das que, outrora, davam

\footnotetext{
10 EMIS - Ministério da Educação, "Situação atual de implementação e projeto", out 2016.

E3 - Revista de Economia, Empresas e Empreendedores na CPLP | Volume 3 | Número 1
} 
resultados pouco animadores em termos de literacia e numeracia e de abandono escolar. Estas escolas estão igualmente a divulgar o ensino bilingue nas línguas oficiais de Timor-Leste: o Tétum Oficial e o Português. As escolas privadas ( $23 \%$ do total $\left.{ }^{11}\right)$ têm grande procura e são uma boa fonte de investimento, nomeadamente as de formações técnicas e as de línguas.

O Ensino Técnico-Vocacional aparece nas intenções de desenvolvimento do Governo, dado o seu potencial para o emprego dos jovens e a qualificação técnica da mão-de-obra. Em 2016, estão em funcionamento 19 escolas.

O número de alunos do ensino universitário passou de 23.460 (com 948 professores), em 2011, para 50.546 (com 2.110 professores), em 201512, em escolas tanto do setor público como do privado. Muitos dos cursos contam, na presente fase, com o apoio de professores estrangeiros, para assegurar a qualidade e a confiança técnica e científica aos alunos e aos empregadores.

\section{Habitação e ordenamento territorial}

A questão central para a resolução dos problemas existentes a nível da reconstrução física das cidades e aldeias de Timor-Leste é a indefinição da propriedade das terras e imóveis. O preenchimento em curso do cadastro das terras e dos prédios e o registo de bens imóveis, bem como a aprovação pelo Parlamento da Lei das Terras e Propriedades, presentemente em apreciação, criarão a médio prazo condições ótimas para o investimento privado no setor. Até lá, as famílias têm vindo a assumir a maior parte da construção das habitações, num cenário de crescimento desordenado, a que os Municípios só agora começam a ter competência para acorrer.

Com efeito, já neste Governo, iniciou-se a criação de Planos de Desenvolvimento Municipal, no qual se pretende que venham a aproximar-se das comunidades as medidas tomadas pelo poder central. Entretanto, o Estado tem em curso programas de apoio à autoconstrução, bem como projetos de habitação de âmbito comunitário. Assim que esteja esclarecido o quadro de propriedade, poder-se-á avançar decididamente para planos de ordenamento locais, provocando um novo impulso na construção civil e tornando os pólos de investimento em potenciais muito atrativos.

\section{Condições Infraestruturais}

Depois de uma fase de dependência de donativos internacionais, para a recuperação do país face à política de terra queimada da violenta retirada dos ocupantes indonésios e para começar a implantar organismos vitais de sobrevivência de um povo martirizado, o Parlamento timorense determinou, em lei de $2005^{13}$, a utilização condicionada das receitas da exploração do petróleo e criou o chamado Fundo Petrolífero. É de facto uma medida sensata que continua a valer a Timor-Leste na construção das infraestruturas nacionais, nomeadamente relacionadas com eletricidade, estradas, instalações prioritárias e intervenções associadas ao saneamento básico. Projetos de grande envergadura que consomem grande parte dos recursos nacionais, mas que, no entanto, são imprescindíveis para o relançamento económico do país como fonte de atração de investimentos.

\section{Eletricidade}

O plano de eletrificação nacional é um motivo de orgulho para Timor-Leste. Partindo quase do zero, neste momento, a eletricidade abrange praticamente todo o território. Zonas de acesso especialmente condicionado utilizam geração elétrica de energias alternativas, tal como a

\footnotetext{
11 Ibid.

12 Dados fornecidos pelo Ministério da Educação.

${ }^{13}$ Lei n. 9 9/2005, de 3 de agosto. A chamada Lei do Fundo Petrolífero sofreu posteriormente diversas atualizações legais.

E3 - Revista de Economia, Empresas e Empreendedores na CPLP | Volume 3 | Número 1
} 
energia solar. A grande maioria da população tem acesso próximo a postos de fornecimento de eletricidade e o país produz mesmo mais eletricidade do que aquela que consome, o que revela ser uma margem positiva para os investidores, de modo a aproveitarem a potência instalada.

\begin{tabular}{|l|l|l|l|}
\hline \multicolumn{2}{|l|}{ Eletricidade } & 40 trimestre de 2011 & 40 trimestre de 2015 \\
\hline Produção & 36.335 milhões KWh & 97.894 milhões KWh \\
\hline Consumo & Doméstico & 10.001 milhões KWh & 25.873 milhões KWh \\
\cline { 2 - 4 } & Comercial & 8.157 milhões KWh & 13.048 milhões KWh \\
\cline { 2 - 4 } & Outros & 3.923 milhões KWh & 4.525 milhões KWh \\
\hline
\end{tabular}

Fonte: Secretaria-Geral do Ministério das Obras Públicas, Transportes e Comunicações.

\section{Água potável e saneamento}

Como retratava o Plano de Desenvolvimento Estratégico 2011-2030: "Grande parte das infraestruturas de água e saneamento urbano em Timor-Leste, incluindo estações de bombeamento, tubos de transmissão, válvulas e tanques, foram danificadas ou destruídas em 1999". Como resultado, "96\% dos domicílios urbanos fora de Díli não têm acesso a 24 horas de abastecimento de água potável. A água só está disponível, em algumas cidades, durante uma hora ou dois dias por semana, visto a capacidade dos sistemas ser inadequada. As nascentes de água corrente também são inadequadas, na maior parte sem tratamento ou fiabilidade: apenas 100 das 400 estações de água no país estão a funcionar.". Hoje, o quadro, apesar de não ser o ideal, revela a sua crescente evolução desde 2011:

\begin{tabular}{|c|c|c|c|}
\hline $\mathbf{2 0 1 5}$ & $\%$ a nível nacional & $\begin{array}{c}\text { \% nas áreas } \\
\text { urbanas }\end{array}$ & $\%$ nas áreas rurais \\
\hline $\begin{array}{c}\text { Abastecimento } \\
\text { de água potável }\end{array}$ & $72 \%$ & $95 \%$ & $61 \%$ \\
\hline $\begin{array}{c}\text { Acesso a } \\
\text { saneamento } \\
\text { melhorado }\end{array}$ & $41 \%$ & $69 \%$ & $27 \%$ \\
\hline
\end{tabular}

Fonte: Secretaria-Geral do Ministério das Obras Públicas, Transportes e Comunicações.

\section{Rede viária}

A rede viária apresenta, em Timor-Leste, problemas complicados, provocados pela orografia e pela qualidade de grande parte dos terrenos, formados por rochas muito friáveis. O Estado comprometeu-se a requalificar as principais rodovias nacionais, em rutura com o isolamento das populações, facilitando o transporte de bens por todo o território. As obras são entregues por concurso a empresas privadas estrangeiras, que empregam muitos habitantes de todo 0 país. Até ao final de 2015, tinham sido reparados e mantidos $1413,78 \mathrm{~km}$ de estradas nacionais. Já em 2016, recebeu-se um grande número de investimentos para o alargamento das principais vias.

Estes projetos de manutenção e melhoramento de estradas nacionais têm providenciado excelentes oportunidades de negócio, que se pretende multiplicar. A preços atuais, a previsão de investimento em recuperação e alargamento de estradas, até 2020, ronda os 1.200 milhões de dólares. Grande parte dos investimentos é apoiada pelo Governo do Japão.

Sobretudo em 2013, mas com um investimento permanente na manutenção e melhoramento de estradas rurais, o Programa Estradas para o Desenvolvimento - R4D, em 2015, contava com $883 \mathrm{~km}$ de pequenas estradas, para resolução de problemas prementes de comunicação em áreas ainda não abrangidas por vias da rede nacional. $O$ efeito evidente da melhoria das vias é a diminuição da sinistralidade rodoviária, que passou de 2.281 acidentes em 2010, para 1943 em 2012, e para 1664 em 2015, segundo dados da Polícia Nacional - PNTL. 


\section{O novo porto de carga, em Tíbar}

No dia 3 de junho de 2016, foi assinado o contrato para conceção, construção e operação da maior infraestrutura de transportes do país, o novo porto da costa norte de Timor-Leste, em Tíbar, 10 quilómetros a oeste de Díli. Trata-se da primeira parceria público-privada no país e traduz um investimento inicial de 278,3 milhões de dólares (148,85 milhões de dólares dos parceiros privados e de 129,45 milhões de dólares do Governo). O consórcio liderado pela empresa francesa Bolloré prevê que as primeiras operações portuárias aconteçam em 2019. Prevê-se uma capacidade inicial de 226 mil contentores por ano, que será ampliada para até um milhão de contentores, com tráfego em dois cais, de 300 e 330 metros, respetivamente.

Esta infraestrutura procura criar condições para posicionar o país nas rotas do tráfego marítimo dos bens que circulam diariamente entre o Pacífico e o Índico.

\section{As Zonas Económicas Especiais}

A 18 de junho de $2014^{14}$ foi criada a Região Administrativa Especial de Oe-Cusse Ambeno (RAEOA) e as Zonas Especiais de Economia Social de Mercado (ZEESM). Pretendeu-se, assim, reduzir as assimetrias regionais e, consequentemente, aumentar a distribuição de riqueza. As ZEESM promovem a atração do investimento e o estabelecimento de empresas nacionais e estrangeiras, com relativa autonomia em relação ao funcionamento geral do país.

A criação da ZEESM da região de Oe-Cusse Ambeno foi motivo para o lançamento quase simultâneo de grande número de projetos-piloto ${ }^{15}$, dos quais se destacam, pela sua variedade e importância no desenvolvimento infraestrutural da região:

- Uma rede de irrigação, que beneficia uma área de 1770 ha;

- A ponte Noefefan Tono, que liga Pante Macassar à estrada para a fronteira ocidental;

- O aeroporto de Oe-Cusse, dimensionado para receber aviões de médio porte; terá inicialmente uma pista com um comprimento de $2,5 \mathrm{~km}$, com previsão de futura extensão;

- A construção da rede viária principal, num total aproximado de $50 \mathrm{~km}$ de estrada;

- Uma central elétrica, com capacidade de produção de $20 \mathrm{MW}$, de apoio e recurso à rede de energia elétrica nacional, que parte da Central de Hera e usufrui das linhas de transmissão indonésias na travessia interfronteiriça terrestre, que separa Timor-Leste do enclave de Oe-Cusse;

- A construção de um barco destinado ao transporte de passageiros e mercadorias, para tráfego entre o Oe-Cusse Ambeno e Díli;

- A aquisição, pela RAEOA, do primeiro avião comercial da República Democrática de Timor-Leste, para uma maior mobilidade dentro do país.

Quanto a Ataúro, o Conselho de Ministros ${ }^{16}$ aprovou, em 2016, o Plano de Ordenamento do Território da llha de Ataúro, que fixa um regime de ocupação, uso e gestão do território compatível com a proteção e valorização dos recursos naturais e com o desenvolvimento das atividades humanas. O principal intuito é manter a qualidade ambiental única e exclusiva da ilha, integrando as dinâmicas sociais e económicas e corrigindo processos que, consequentemente, poderiam conduzir à degradação da extraordinária riqueza natural daquele espaço.

\footnotetext{
${ }^{14}$ Cf. http://www.mj.gov.tl/jornal/?q=node/6670 .

${ }^{15} \mathrm{Cf}$. http://zeesm.com/pt-pt/category/projectos-pt/.

${ }^{16}$ Cf. http://timor-leste.gov.t//?p=14450\&lang=pt .

E3 - Revista de Economia, Empresas e Empreendedores na CPLP | Volume 3 | Número 1
} 


\section{Condições económicas}

Passados 14 anos sobre a independência de Timor-Leste, mas apenas 4 sobre a retirada das forças de manutenção de paz das Nações Unidas, o país goza hoje de uma governação estável e democrática, avançando aplicadamente no processo de desenvolvimento económico. Timor-Leste tem a economia de mais rápido desenvolvimento no Pacífico, com um crescimento anual composto em 5 anos de 11,5\%, de acordo com dados de 2014 da Heritage Foundation, com sede em Washington. Em 2014, as Nações Unidas elevaram Timor-Leste de "País com baixo índice de desenvolvimento humano" para "País com índice médio de desenvolvimento humano", no seu Relatório de Desenvolvimento Humano, a par da África do Sul, Índia e Indonésia.

Timor-Leste não tem moeda própria e utiliza o dólar americano, o que representa uma vantagem para o investimento, pois trata-se de uma moeda forte, de grande utilização por todo o mundo. O país é o menos endividado do mundo (World Economic Forum - WEF, dados de 2015), com o Fundo Petrolífero a marcar o alto nível de poupança nacional (em apenas 9 anos, o fundo atingiu 16,6 mil milhões de dólares, com elevado retorno, devido a uma gestão criteriosa).

Ainda segundo dados do WEF, o peso global dos impostos é dos mais baixos do mundo. $O$ Banco de Desenvolvimento Asiático estima a inflação de 2016 no país em 2\%, e em 3\% para o próximo ano (Asian Development Outlook 2016), o que significa uma diminuição significativa em relação a anos anteriores. Já o aumento do investimento público e privado deverá imprimir uma aceleração ao crescimento económico de Timor-Leste, que atingirá os 4,5\% este ano e os 5,5\% em 2017.

As receitas estão altamente associadas aos rendimentos do setor petrolífero - cerca de $89 \%$ em 201517. A concorrência é fraca em vários domínios; mas conhecem-se índices de boa competitividade em alguns setores, nomeadamente no café.

O grande desafio que o atual Governo enfrenta agora é, pois, o da diversificação económica, onde o campo está aberto a praticamente todos os investimentos, com índices de concorrência interna muito atraentes para os investidores.

\section{Adesão a organizações internacionais}

Timor-Leste mantém relações de grande cordialidade e acordos bilaterais e regionais com uma série de centros de produção de conhecimento e riqueza mundial, mais precisamente com a China, a Austrália, o Japão e a Coreia do Sul, entre muitos outros. Mas, para além dessas relações estabelecidas diretamente, o país aposta também nas sinergias e redes de interconexão resultantes da participação em organizações internacionais, culturais e económicas, factor de atração para as trocas comerciais e investimento entre os países que as compõem.

As organizações internacionais alargam os mercados e melhoram as condições competitivas dentro dos países federados, criando medidas que podem facilitar a circulação de matériasprimas e mercadorias, através das fronteiras conjuntas e da redução dos custos de transporte. A posição geoestratégica do país torna-se cumulativa, com a adesão à CPLP e com a negociação da adesão à ASEAN, facilitando o seu acesso aos grandes pólos que se encontram em expansão económica no mundo.

\section{CPLP}

Como antiga colónia de Portugal, foi óbvia a adesão de Timor-Leste à Comunidade de Países de Língua Portuguesa (CPLP), na qual está incluído o Brasil e diversos países africanos, para além da antiga metrópole colonizadora europeia. Nos seus países membros, reúne-se uma população de mais de 260 milhões de pessoas, em 4 continentes e com interessantes ligações

\footnotetext{
17 CSIS ASIAN Program, "By the numbers: Timor-Leste's Economy", em www.cogitasia.com/by-the-numbers-timorlestes-economy/, consultado a 20 de agosto de 2016.

E3 - Revista de Economia, Empresas e Empreendedores na CPLP | Volume 3 | Número 1
} 
económicas a partir de vários deles, constituindo uma ponte para o mercado da União Europeia.

A área terrestre de todos os Estados-membros da CPLP, somada, representa cerca de 11 milhões de quilómetros quadrados, com recursos naturais muito relevantes, a que se acrescenta uma costa marítima de enorme riqueza, que alarga o seu potencial económico e a sua importância estratégica.

A CPLP procura estimular o desenvolvimento de projetos empresariais entre os Estadosmembros, visando o reforço dos setores privados de cada um deles e aproveitando as transferências tecnológicas e de conhecimento favorecidas pela organização.

Nos últimos dois anos, Timor-Leste assumiu a Presidência Rotativa da CPLP. Entre as dezenas de iniciativas que promoveu e organizou nesse âmbito, conta-se a II Reunião de Ministros do Comércio, realizada a 24 de fevereiro de 2016. Foi um passo importante para os países membros extraírem o máximo potencial da organização, através de diversas medidas, tais como:

- A partilha de experiências, informações e boas práticas;

- A adoção de medidas concretas de promoção do comércio e do investimento entre os Estados-membros;

- A criação de "clusters" nos setores estratégicos;

- A promoção de feiras e eventos comerciais;

- A criação de um fórum para as agências de promoção de comércio e investimento dos Estados-membros;

- O desenvolvimento de ações de divulgação de programas de formação para PME e para o setor público em matérias relevantes para o comércio e o investimento, nomeadamente programas em plataformas digitais;

- O desenvolvimento de sistemas de garantia para coberturas de risco à exportação no espaço da CPLP;

- A supressão de vistos entre os Estados-membros, sobretudo no que diz respeito à classe empresarial;

- A procura de financiamentos para a acreditação e a certificação de laboratórios a nível internacional, como preenchimento das condições de certificação de origem da Organização Mundial do Comércio (OMC).

As características heterogéneas das realidades económicas, sociais e políticas dos Estadosmembros colocam desafios que, sucessivamente, vão cedendo espaço às vantagens resultantes da expansão de mercados e de fluxos de investimento, bem como da transferência de conhecimentos e de experiências no atual mundo globalizado.

\section{ASEAN}

A localização estratégica no sudeste do continente asiático cedo orientou a política timorense para a adesão à Associação de Nações do Sudeste Asiático - ASEAN, o que recentemente se constituiu como mercado único, afirmando-se como o pólo mais importante da economia asiática entre a Índia e a China. Reúne $8,8 \%$ da população mundial e é um espaço económico de grande riqueza com um enorme potencial de crescimento. Neste século de incontornável emergência económica asiática, a ASEAN possibilita a países mais pequenos acompanharem e enfrentarem os colossos mercados, chinês e indiano, que apostam na evolução tecnológica, na qualificação dos seus recursos humanos e na mobilização de financiamentos para se imporem na economia internacional.

Timor-Leste quer integrar esse esforço de reação regional concertada e tem vindo a desenvolver incessantes diligências diplomáticas, usufruindo presentemente do estatuto de observador. Paralelamente, as principais reformas em curso no país estão a ser realizadas tendo em conta as exigentes normas da ASEAN, com vista a abreviar o exigente processo de adaptação que comporta aquela adesão em particular.

E3 - Revista de Economia, Empresas e Empreendedores na CPLP | Volume 3 | Número 1 
É na região da Ásia-Pacífico que se joga uma parte fundamental do futuro de Timor-Leste. Desde há muito que se registam relações comerciais substanciais com os países da ASEAN, tanto ao nível das importações como das exportações não petrolíferas do país. A adesão à organização permitirá aumentar as exportações, através da redução de tarifas aduaneiras e da facilitação do comércio. Tornando-se membro pleno da ASEAN, Timor-Leste beneficiará ainda dos acordos de comércio livre que aquela organização estabeleceu com a China, Índia, Japão, Coreia, Austrália e Nova Zelândia, entre outras economias da região.

Os países membros da ASEAN têm vindo a facilitar o fluxo de bens e serviços na região, reduzindo os custos de produção e os impostos. A organização tem estado muito ativa no sentido de promover medidas de normalização de procedimentos e de liberalização dos serviços, especialmente em termos do transporte aéreo regional.

\section{Condicionantes ao investimento}

O investimento, em Timor-Leste, está aberto para qualquer setor de atividade económica legal, à exceção da distribuição ou venda de armamento ou munições, de iniciativas que possam interferir com a legislação ambiental vigente e de alguns setores legalmente especificados. Ainda que esteja prevista na lei a possibilidade de participação de investidores privados mesmo na indústria mineira e petrolífera, venda direta de bens e equipamentos ao consumidor final e comercialização de propriedades.

Os direitos de propriedade estão consagrados na lei e em vigor. A lei de terras está em debate no Parlamento e envolve situações muito diversificadas e sensíveis, que se prendem com a sobreposição do direito ancestral (não escrito, mas coletivamente legitimado) e dois administradores estatais sucessivos, com leis próprias: os colonizadores portugueses, durante séculos, e o ocupante indonésio, durante 24 anos. Está em execução o Cadastro de Propriedades, sendo, neste momento, o Estado o detentor provisório de grande parte dos terrenos abandonados pelos anteriores proprietários.

A Constituição veda claramente a propriedade do solo a estrangeiros, mas a lei dá garantias do direito de uso. Aos investidores estrangeiros é aconselhado que recorram aos serviços do Estado para confirmação da situação de qualquer terreno de interesse, antes de fazerem negócio direto com proprietários que podem vir a ser legitimamente contestados nesse papel.

\section{Reforma legal de apoio ao comércio internacional}

Reconhecendo limitações jurídicas e administrativas na gestão da atividade económica, o Governo de Timor-Leste iniciou um processo de profunda reforma aduaneira e fiscal. Em fevereiro deste ano, aprovou a criação da Comissão Nacional para a Facilitação do Comércio (CONFAC), um "fórum consultivo de promoção do diálogo entre o Executivo, o setor privado e outros intervenientes relevantes na área do comércio".

Entretanto, está em curso a elaboração de novas leis sobre o investimento e atividades comerciais, que pretendem dar mais garantias aos investidores. Complementarmente, está também a proceder-se a uma reforma das Alfândegas, que visa reduzir atrasos e facilitar o trabalho aos transitários.

Até 2018, os serviços aduaneiros vão ser totalmente reformulados, a fim de tornar mais fácil para as empresas importar e exportar bens, e ajudar o Governo a cobrar receitas de uma forma justa e transparente.

Esta reforma, em curso desde 2014, visa, por diversos meios, aumentar a eficiência das Alfândegas através da simplificação e padronização de processos, alinhando-os com as melhores práticas internacionais. Está a proceder-se à codificação internacional de todas as mercadorias, em conformidade com as normas da ASEAN. A modernização dos sistemas tecnológicos e a formação especializada dos funcionários estão também contemplados. Estão a ser criados processos de auto-avaliação para simplificar o desalfandegamento e de integração das diferentes plataformas digitais envolvidas em toda a tramitação alfandegária.

E3 - Revista de Economia, Empresas e Empreendedores na CPLP | Volume 3 | Número 1 
Procura-se, fundamentalmente, adotar procedimentos aduaneiros modernos, simples e eficientes.

Neste momento, está atualizado o Código de Procedimentos Aduaneiros; e o Sistema Harmonizado de 2012 foi padronizado em conformidade com as exigências em vigor na ASEAN. Deu-se início à primeira fase de transição de dados aduaneiros para o sistema automatizado de terceira geração ASYCUDA World. Iniciou-se o processamento eletrónico de contentores e concluiu-se a estruturação da unidade central e a formação dos despachantes.

A Alfândega passará a justificar os atrasos no processamento de carga e a ser responsável por outras decisões, tais como apreensão de mercadorias ou recusa de licenças. Os importadores, por seu turno, terão direito a procedimentos de recurso formal. A Alfândega terá que prestar informações precisas a importadores e exportadores e passará a manter um registo centralizado de informações, de acesso gratuito. Será criado um "call center" para importadores e exportadores. As inspeções físicas de contentores só se realizarão se o contentor for suspeito, se o importador não tiver fornecido todas as informações necessárias e por uma seleção aleatória. Todos os outros contentores serão processados eletronicamente, aumentando a capacidade de processamento e reduzindo os custos para os importadores.

O sistema ASYCUDA World ajudará a determinar quais os contentores que devem ser verificados, através da criação de "perfis" de empresas e contentores. Todos os passos do processo de importação de mercadorias serão realizados eletronicamente. $O$ tempo de processamento de cargas compatíveis vai passar para apenas 12 a 36 horas.

Timor-Leste está a avançar no processo de adesão como membro à Organização Mundial do Comércio (OMC), mas o Governo está a adaptar as práticas comerciais e económicas do país aos termos do Acordo de Facilitação do Comércio da OMC. É o caso do novo Código Aduaneiro, que aproxima os procedimentos de Timor-Leste dos praticados na ASEAN.

Nos termos do Acordo de Facilitação do Comércio, Timor-Leste prepara-se para adotar várias medidas, nomeadamente:

- Publicar e disponibilizar na internet informações regularmente atualizadas sobre as regras a respeitar na importação e exportação;

- Aplicar taxas nas agências fronteiriças e de quarentena que reflitam o custo real da prestação do serviço a ser fixado;

- Colocar as agências de fronteira em cooperação entre si, juntamente com as alfândegas de outros países, agilizando as operações de controlo;

- Realizar e publicar estudos de regulares de tempos de desalfandegamento - sendo que, desde o final de 2014, Timor-Leste realizou três estudos deste tipo, para medir e melhorar a eficiência.

Timor-Leste está a preparar uma plataforma de janela única (reunião dos balcões únicos de cada país) que servirá os países da CPLP e da ASEAN. Com efeito, as alfândegas geram dados importantes sobre importações e exportações. Estes dados passarão a ser tratados por um sistema harmonizado, tendo sido desenvolvido especificamente para Timor-Leste e que irá gerar informações relevantes para as empresas nacionais e internacionais.

Este sistema está alinhado pelo da ASEAN, o que permitirá às empresas compararem facilmente os dados de Timor-Leste com os de todos os outros países daquela Associação. Este tipo de informação, que o Governo timorense confia, ajudará a atrair mais investimentos para o país.

\section{Apoios ao investimento}

O Governo de Timor-Leste está fortemente empenhado em acelerar o ritmo das reformas, de forma a poder criar condições para incentivar os investidores privados a aplicar recursos significativos, tanto financeiros como técnicos, no país. Reconhecendo a necessidade de criar um clima de confiança para o investimento, têm vindo a ser criados serviços, leis e incentivos, E3 - Revista de Economia, Empresas e Empreendedores na CPLP | Volume 3 | Número 1 
que estão a revolucionar as condições de funcionamento do aparelho estatal em matéria económica.

Anteriormente, a carga burocrática prejudicava os investidores com requisitos administrativos dispersos por vários serviços. Os pioneiros do investimento em Timor-Leste esperavam meses pelas licenças de lançamento do seu negócio. Hoje, os procedimentos estão muito agilizados.

\section{Tradelnvest - $O$ balcão único do investidor}

A Tradelnvest é a agência de promoção de investimento e exportação de Timor-Leste, que ajuda potenciais investidores na identificação de projetos de negócio no país. A criação de uma estrutura de balcão único ("one-stop shop") era uma necessidade já identificada, para facilitar a informação e organização dos investidores. Hoje, contam com um verdadeiro parceiro de negócios, capacitado para fornecer análises sobre o ambiente empresarial timorense, através da apresentação de oportunidades de investimento, orientação no terreno, obtenção de autorizações e licenças, informação sobre impostos, incentivos à exportação e todos os procedimentos corretos que ajudam a definir e a concretizar projetos num curto espaço de tempo. A competência deste serviço alarga-se mesmo ao apoio pós-investimento.

As propostas de investimento passam a entrar pela Tradelnvest, consequentemente encaminhas para a Comissão de Avaliação do Investimento Privado e Exportação, que deteta e resolve atempadamente eventuais estrangulamentos administrativos.

\section{SERVE - Serviço de Registo e Verificação Empresarial}

A criação do SERVE - acrónimo feliz para o serviço do Estado responsável pelo registo de empresas e de empresários em nome individual - veio concentrar num serviço único as funções inerentes à concretização do registo comercial, anteriormente dispersas por serviços de vários Ministérios. Com este esforço de agilização, hoje os pedidos de registo são processados no período máximo de 5 dias úteis (sendo em média 3 dias úteis). Em abril de 2014, o SERVE criou um sistema de tratamento específico de pedidos de registo de Empresário em Nome Individual e de Sociedade Unipessoal Limitada, que passou a dar resposta em apenas um dia.

\section{Legislação}

A Lei do Investimento Privado (Lei $n .$. 14/2011) traçou o essencial do quadro jurídico de promoção do investimento em Timor-Leste. Passados 5 anos, está agora em revisão, para atualização de procedimentos, adaptação às orientações do Acordo Global de Investimento (ACIA) da ASEAN e compatibilização do regime jurídico do investimento privado com a legislação tributária nacional incluída no Programa de Reforma Fiscal em curso.

Tomando a experiência acumulada dos últimos anos e a evolução das melhores práticas internacionais, pretende-se introduzir na lei aquilo que é já assumido na missão da Tradelnvest: melhorar a atenção e qualidade de serviços ao investimento privado e cuidar do investidor na fase pós-investimento. Há uma preocupação em tornar mais transparente 0 tratamento de igualdade entre investidores nacionais e externos, bem como os direitos e deveres dos investidores, e reforçar as garantias de propriedade privada, dentro dos limites constitucionais. A importação de bens e equipamentos, a exportação dos produtos produzidos, o recurso ao crédito, a livre transferência de fundos para o estrangeiro, a livre contratação de trabalhadores estrangeiros, a proteção da propriedade intelectual e o respeito pelo sigilo profissional, bancário e comercial, estão a ser igualmente objeto de reanálise, no sentido da flexibilização da promoção do investimento privado no país.

O Certificado de Investidor foi uma das importantes medidas regulamentadas na Lei do Investimento. Entre 2011 e maio de 2016, foram passados 67 Certificados de Investidor (37 a investidores timorenses e 30 a estrangeiros), representativos de investimentos de mais de, 
respetivamente, 182 milhões de dólares e 587 milhões de dólares ${ }^{18}$. Trata-se de um documento identificativo que atesta os direitos, deveres e benefícios do investidor e serve de base a todas as operações relativas ao seu investimento. Com a sua apresentação, os serviços públicos vêem-se obrigados a prestar um serviço célere de atendimento.

Para projetos ou empreendimento de investimento que, pela sua dimensão ou natureza ou pelo respetivo impacto económico, social, ambiental ou tecnológico, possam ser de especial interesse para o País, no quadro do Plano Estratégico de Desenvolvimento Nacional, o Estado poderá negociar benefícios especiais com o investidor.

\section{Incentivos fiscais}

Os benefícios aos investidores são regulados por decreto governamental. Presentemente, aplicam-se a investimentos e reinvestimentos mínimos de 50 mil dólares, para agentes nacionais, e de 1 milhão e meio de dólares, para investidores estrangeiros ${ }^{19}$. Envolvem isenções integrais de impostos sobre rendimentos, taxas de importação, comercialização e serviços, para além de permitirem arrendamentos de propriedades por um período máximo de 100 anos (50 anos, renovável por outros tantos).

\section{Proteção ao Investidor}

A proteção dos investimentos, prevista na Lei n.․14/2011, é um dos aspetos que o Governo se propõe alargar, na revisão daquele diploma, que está em apreciação. De qualquer modo, a lei "garante o direito à propriedade privada para fins de desenvolvimento de projectos de investimento ou reinvestimento, sujeito aos limites previstos pela Constituição e na legislação sobre terras" e "o Estado obriga-se a não adoptar uma política de nacionalizações que prejudique deliberadamente o empreendimento do investidor em território nacional" (art. 14..$^{\circ}$ ); dará a "todos os investidores igual acesso aos tribunais para defesa dos seus direitos e interesses legalmente protegidos" (art. 13. ${ }^{\circ}$ ), sendo que "todos os investidores podem proceder à importação de bens e equipamentos e à exportação dos produtos produzidos" (art. 15..$^{\circ}$ ), "podem recorrer livremente ao crédito interno e externo para financiamento do empreendimento" (art. 16..$^{\circ}$ ); e podendo garantir aos investidores externos "o direito de livre transferência de fundos provenientes de qualquer investimento em Timor-Leste para 0 estrangeiro" (art. 17. ${ }^{\circ}$ ). Para além disso, está protegido o direito à propriedade intelectual (art. $19 .^{\circ}$ ) e "o respeito pelo sigilo profissional, bancário e comercial" (art. $20 .^{\circ}$ ).

\section{Áreas de oportunidade de investimento}

Timor-Leste apresenta muitas oportunidades para o investimento estrangeiro em praticamente todos os setores. O Plano Estratégico de Desenvolvimento aponta as vantagens óbvias do país: os recursos naturais, a localização geográfica e o perfil económico.

De facto, os recursos naturais e minerais são significativos, tanto em terra como no mar. A sua exploração e o potencial geoestratégico do país, situado num dos quatro corredores marítimos mais utilizados na ligação entre os oceanos Índico e Pacífico, permitem encarar com otimismo os desafios da diversificação económica, potencializada para contribuir para o incremento do comércio mundial. No âmbito da agricultura, silvicultura e pesca, o país tem um enorme potencial de produção com vista à exportação e à substituição de importações.

\footnotetext{
${ }^{18}$ Entre os investimentos estrangeiros neste período, destacam-se os de investidores australianos (437 milhões de dólares), indonésios (57 milhões) e de Singapura (47 milhões); outros investidores da região da Ásia-Pacífico são da China, Filipinas, Ilhas Fiji, Índia, Malásia, Papua-Nova Guiné e Vietname. Fora deste âmbito geográfico, nos últimos 5 anos apenas se registou um investimento espanhol e um dos Estados Unidos. Desde 2008, foram passados 179 certificados, num montante global de cerca de 1445 milhões de dólares, dos quais 964 milhões provenientes de investidores estrangeiros. - Dados facultados pela Tradelnvest em junho de 2016.

${ }^{19}$ Prevê-se a revisão deste montante a breve prazo, de modo a alargar os benefícios a pequenos investimentos.
}

E3 - Revista de Economia, Empresas e Empreendedores na CPLP | Volume 3 | Número 1 


\section{Agropecuária}

O aumento das exportações de produtos agrícolas é um dos vetores fundamentais de diversificação económica de Timor-Leste. A modelização económica realizada pelo Governo veio confirmar que Timor-Leste pode aumentar substancialmente as receitas de muitas plantas industriais, nomeadamente o café, cacau, caju, iguape, coco, pimenta, cravinho e baunilha. $\mathrm{Na}$ silvicultura, variedades como a teca, sândalo e pau-rosa merecem ser cultivadas em escala comercial.

Timor-Leste pode exportar alguns produtos diretamente e tem potencial para realizar mais processamento de produtos agrícolas dentro do país. As exportações de produtos processados podem preencher nichos de mercado, do qual se salienta o dos produtos agrícolas orgânicos. Com efeito, Timor-Leste é um dos únicos países do mundo onde a agricultura orgânica é predominante, o que lhe dá uma vantagem competitiva na produção de alta qualidade, com procura em estratos elevados dos mercados de todos os continentes.

O Plano Estratégico de Desenvolvimento Nacional (PEDN) aponta para a necessidade de introduzir novos métodos de cultivo, colocando Timor-Leste no caminho da autossuficiência na produção de arroz, já em 2020. Com a agricultura de subsistência sendo progressivamente substituída por uma agricultura de perfil comercial, mesmo que produzida por pequenos proprietários, são previsíveis excedentes de produção que podem ser transformados localmente e exportados. É sobretudo nestes domínios - de transformação e exportação - que se abrem excelentes oportunidades de investimento.

O limite é praticamente o da imaginação, pois, apesar de pequeno, o território possui climas diversificados e propícios, quer para culturas tropicais, quer de zonas temperadas. Não seria 0 primeiro país a produzir plantas aromáticas requintadas, no entanto tem a vantagem de entrar no estrato mais elevado da comercialização em perfumaria, sendo hoje muito raro encontrar produções biológicas nesse domínio, devido à adulteração da qualidade provocada por pesticidas e adubos artificiais. De igual modo, a indústria farmacêutica procura plantas com uma qualidade que poucos países podem fornecer perante a pureza orgânica de Timor-Leste. Associadas a esta riqueza, produções como o mel têm em Timor-Leste terrenos de eleição, em harmonia com a preservação ambiental defendida no Plano Estratégico. Também a produção de aves e gado, nomeadamente em produção biológica, tem um futuro promissor para mercados exigentes, como o Japão e Singapura.

\section{Pescas}

Globalmente, um quinto de toda a proteína animal consumida por seres humanos vem de ambiente marinho. Timor-Leste tem um imenso potencial de pesca nas suas águas territoriais. As capturas marítimas têm vindo a ser facilitadas através de licenças de pesca concedidas a empresas chinesas e coreanas. Não é difícil imaginar os resultados de um investimento equilibrado numa frota de pesca respeitadora dos fundos marinhos e das necessidades reprodutivas das espécies.

Se a pesca for bem gerida, os recifes podem produzir, em média, 15 toneladas de peixes e outras espécies de interesse económico por quilómetro quadrado, por ano. O Banco Mundial, num estudo sobre recifes no sudeste asiático, aponta enormes valores de riqueza, que têm vindo a ser desbaratados, em especial pela Indonésia, com a destruição dos recifes de coral. Mas há também um potencial a explorar na aquacultura marinha, nomeadamente em viveiros de marisco e outras espécies de água salgada, em zonas costeiras delimitadas. A experiência de produção de algas em Ataúro pode também servir de inspiração a novos investidores.

No interior, as experiências de aquacultura de água doce, com espécies como a tilápia, têm tido êxito assinalável e devem ser reproduzidas, tanto por questões de segurança alimentar do país - uma das prioridades do PEDN - como também para a criação de emprego em zonas carenciadas e para exportação. 


\section{Turismo}

O Plano Estratégico aponta como modelo a desenvolver o do turismo ambientalmente sustentável, respeitador da cultura e do património das comunidades locais. Apesar da presente falta de infraestruturas de apoio, o país tem acolhido um número crescente de turistas, especialmente enquanto destino de aventura. A demarcação de diversos Parques Naturais e outras zonas de paisagem protegida, sendo de destacar a zona marítima, que são um contributo importante, neste domínio.

A tranquilidade que as diferentes paisagens e a pureza do ambiente inspiram, seja no mar ou na montanha, é também um factor de importância para segmentos de Turismo mais voltados para o lazer na natureza e para o turismo de Saúde, terapêutico.

Os recifes de coral são um grande atrativo para os mergulhadores, pescadores recreativos e para quem procura férias ao sol - algumas das melhores praias são mantidas através da erosão natural dos recifes nas proximidades, bem patente na costa de Timor-Leste. Foram essas praias que deram fama e proveito aos investidores turísticos de diversas partes do mundo, nomeadamente nas Caraíbas e na Polinésia.

Águas tropicais ricas em vida marinha, recifes de coral até à costa, praias de areia branca, montanhas espetaculares, cultura timorense única, história de enorme riqueza: com semelhantes atrativos, conquistar visitantes, nomeadamente asiáticos, não apresenta grandes dificuldades para Timor-Leste. O investimento deve aproveitar este potencial e preservá-lo para sua vantagem. No que diz respeito ao turismo de lazer ou de nível profissional, as possibilidades estão todas em aberto.

\section{Infraestruturas}

Assim falava, já em 2014, o então Ministro dos Transportes e Comunições ao The Japan Times ${ }^{20}$ :

Não queremos apenas melhorar as infraestruturas existentes. Queremos construir um novo aeroporto e dois portos marítimos, um na costa sul e outro em Oe-Cusse. Os estudos de viabilidade foram feitos [...]. Gostaríamos de desenvolver a maioria dos projetos através de Parcerias Público-Privadas.

A localização geo-estratégica de Timor-Leste permite fazer do país uma placa giratória para o comércio mundial na região Sudeste Asiática. Estão em aberto grandes projetos, aguardando investidores, tanto na área dos aeroportos, como dos portos, estradas e transportes.

\section{Indústria ligeira}

A indústria ligeira é um excelente complemento para as atividades primárias a desenvolver no país e uma forma de diversificar a economia timorense, como se afirma no Plano Estratégico de Desenvolvimento 2011-2030. A população jovem de Timor-Leste fornece uma excelente força de trabalho e mão de obra para investidores que procurem produzir bens, tanto para 0 mercado interno como para a exportação.

\section{Indústria alimentar}

Timor-Leste está imensamente carenciado de uma rede de frio que potencie a comercialização em fresco e os produtos de transformação da sua produção alimentar. É um setor infraestrutural de grande interesse económico e com múltiplas aplicações no território.

Entretanto, o setor conheceu o primeiro grande investimento estrangeiro: a terceira maior produtora de cerveja do mundo, a holandesa Heineken, que acaba de investir cerca de 40 milhões de dólares na construção de uma fábrica de cerveja e refrigerantes, próxima de Díli. 0

\footnotetext{
20 Cf. "Improving infrastructure is top priority" in The Japan Times, 2 de maio de 2014.

E3 - Revista de Economia, Empresas e Empreendedores na CPLP | Volume 3 | Número 1
} 
projeto prevê 200 postos de trabalho diretos, a terminar um processo acelerado de formação, e 800 indiretos. $\mathrm{O}$ início da produção está previsto para dezembro deste ano.

\section{Petróleo e gás natural}

A riqueza do Mar de Timor em hidrocarbonetos tem sido de enorme importância no desenvolvimento de Timor-Leste. Apesar das iniciativas crescentes para a diversificação da economia nacional, não se pode passar ao lado de um potencial equivalente a mais de 6,3 mil milhões de barris de petróleo, a explorar nos próximos 50 anos.

A empresa pública TIMORGAP está presentemente concentrada no projeto Tasi Mane, aquele que mais interesse tem suscitado junto de investidores. Esta compreende três agrupamentos que se desenvolvem ao longo da costa sul:

- A base logística do Suai, de apoio às atividades de petróleo e gás "offshore";

- O complexo industrial de Betano, que será composto por uma refinaria e serviços de apoio;

- A área de Beaço, destinada ao gasoduto que transportará o gás natural proveniente do Mar de Timor, estando prevista a construção de uma fábrica para processamento do referido gás.

O Governo tem vindo a regulamentar as diferentes atividades do setor do petróleo e do gás, "offshore" e "onshore", como é exemplo a muito recente regulamentação da subdivisão do bloco de exploração "onshore"21, com o propósito de aumentar a sua atratividade para o setor privado.

\section{Outras indústrias: Indústria médica e farmacêutica}

Os cientistas estão a voltar-se para os oceanos em busca de novas curas para infeções bacterianas cada vez mais resistentes aos antibióticos ${ }^{22}$. Os recifes de coral são uma grande promessa nesse campo pela variedade de substâncias químicas produzidas por muitos dos organismos que os formam e habitam. Os corais já estão também a ser utilizados com grande êxito para enxertos ósseos.

\section{Indústria cimenteira}

No âmbito da construção de infraestruturas essenciais ao desenvolvimento do país, o Governo assinou, a 17 de maio do corrente ano, um acordo especial de investimento com a TL Cement, para a construção de uma fábrica de cimento. Esta ficará localizada em Baucau, uma região com calcário de grande qualidade. Acreditando nos beneficios da construção desta instalação, o Governo foi mais além, aprovando, em novembro de 2016, a participação do Estado na sociedade comercial TL Cement, procurando, desta forma, dar um sinal positivo a investidores nacionais e estrangeiros. O início da produção e fornecimento de cimento está previsto para os primeiros meses de 2018.

\section{Porquê investir em Timor-Leste?}

Timor-Leste tem sido um aluno aplicado no que diz respeito às relações internacionalmente estabelecidas com bancos, organizações para o desenvolvimento e instituições de sucesso em diferentes áreas. O país acompanha com atenção casos de estudos internacionais com pontos de contacto com a sua realidade.

\footnotetext{
21 Aprovada pelo Conselho de Ministros a 22 de novembro de 2016.

22 "Coral reefs are sometimes considered the medicine cabinets of the 21 st century. Coral reef plants and animals are important sources of new medicines being developed to treat cancer, arthritis, human bacterial infections, Alzheimer's disease, heart disease, viruses, and other diseases." Fonte: Departamento de Comércio dos EUA - Administração Nacional para os Oceanos e a Atmosfera (NOAA), "What does coral have to do with medicine?", http://oceanservice.noaa.gov/facts/coral medicine.html, página consultada a 21 de maio de 2016.

E3 - Revista de Economia, Empresas e Empreendedores na CPLP | Volume 3 | Número 1
} 
O seu pequeno mercado interno e o fraco poder aquisitivo da população são apenas limitações para aqueles que não se apercebam do que o país tem de mais atraente em termos económicos. A diversidade e conservação dos recursos naturais, em terra e no mar, abrem perspetivas quase ilimitadas em termos de agricultura, pescas e manufaturas associadas, com amplas perspetivas para a exportação. A beleza paisagística, a tranquilidade de todo 0 território, a amabilidade e as manifestações culturais identitárias do seu povo, sugerem retornos muito interessantes para investimentos turísticos voltados para os mercados emergentes próximos e para nichos de elites mundiais sedentas de usufruir dos últimos paraísos na Terra.

A integração de Timor-Leste em associações de charneira multicontinental, das quais se destaca a Comunidade de Países de Língua Portuguesa, abre perspetivas de trocas comerciais facilitadas com a Europa, África e América do Sul. Os esforços em curso para uma rápida adesão à Associação das Nações do Sudeste Asiático colocarão o país em posição de charneira para exportações em vastos mercados emergentes e em rápido desenvolvimento.

Timor-Leste é uma nação com visão, humildade e ambição. O caminho percorrido na última década e meia tem pouco paralelo no mundo. Saído de uma economia de fraca subsistência, sem os mínimos em praticamente nenhum setor, o país aproveitou a disponibilidade da cooperação internacional para limpar os escombros, estancar as feridas, evitando que infetassem as relações futuras e recuperando confiança sobre a sua capacidade de integração no mundo. Apesar da sua pequena dimensão e experiência, traçou um rumo detalhado para não se perder em opções secundárias e ignorar oportunidades que servem objetivos de construção. Timor-Leste tem vindo a assentar bases sólidas em todas as direções da vida política e social.

Tudo isto foi possível graças à incrível resiliência do povo timorense, que merece o melhor, aos apoios internacionais, que não nos cansamos de agradecer, e aos dividendos do petróleo, esse maná que nos habita e que nos deu o sofrimento e a possibilidade do renascimento. Quem viu Timor-Leste em qualquer momento a seguir ao referendo do final do milénio e hoje visita o país percebe, sem dificuldade, onde têm sido aplicados estes tesouros.

É chegado o momento de darmos um novo salto qualitativo, no sentido da plena integração na economia mundial, propondo ao exterior parcerias de negócio, nichos de mercado num território praticamente virgem, uma pousada estrategicamente colocada entre vários oceanos, várias sensibilidades culturais, várias organizações internacionais.

A visão que Timor-Leste tem para o futuro do seu povo passa por diversificar a sua economia, abrindo-se ao investimento estrangeiro para, em conjunto, alcançar resultados mutuamente proveitosos, a par do desenvolvimento económico e social. O nosso grande objetivo internacional de momento é dar a conhecer a oportunidade de oferta que Timor-Leste representa. Tratando-se de um pequeno paraíso quase inexplorado, onde quase todo 0 investimento pode ser pioneiro, Timor-Leste é, acima de tudo, o local certo para projetar pequenos, médios e grandes negócios.

Em suma, Timor-Leste procura negócios que sirvam o seu povo e dêem os justos dividendos aos investidores, independentemente dos montantes em causa. É isso que entendemos por investimento para todos.

\section{Investir em Timor-Leste \\ Interlocutor central para o Investimento ("one-stop shop"): Tradelnvest -Timor-Leste www.investtimor-leste.com}

Registo rápido e online (SERVE): 1 a 2 dias

Certificado de Investidor: 30 a 180 dias

Investimento mínimo para benefícios fiscais:

_ investidores nacionais: 50 mil dólares

- estrangeiros e nacionais não residentes: 1.500 .000 dólares

E3 - Revista de Economia, Empresas e Empreendedores na CPLP | Volume 3 | Número 1 
- empresas mistas com controlo de $75 \%$ por nacionais residentes: 750.000 dólares

Isenção de impostos:

- durante 5 anos em Díli e Baucau

- durante 8 anos noutros Municípios

"Leasing" de terrenos do Estado: até 50 anos (possibilidade de renovação por mais 50)

Pontos fortes:

- localização geoestratégica no Sudeste Asiático

- bom relacionamento internacional

- mercado interno desejoso de substituir importações

- vastos mercados externos nas proximidades

"Building a nation is among the most worthwhile of human endeavors. It is not just a job, but a calling - and a commitment."

Agio Pereira

\section{Referências}

CIA, World Fact Book, consultado a 20 de maio de 2016.

CSIS ASIAN Program, "By the numbers: Timor-Leste's Economy", in cogitasia.com/by-thenumbers-timor-lestes-economy/, consultado a 20 de agosto de 2016

Departamento de Comércio dos EUA - Administração Nacional para os Oceanos e a Atmosfera (NOAA), "What does coral have to do with medicine?", http://oceanservice.noaa.gov/facts/coral medicine.html, página consultada a 21 de maio de 2016.

EMIS - Ministério da Educação, "Situação atual de implementação e projeto", out 2016.

Instituto de Estatística, Demographic and Health Survey, "2000-2015: Perfis de Saúde de Timor-Leste - Progressos", apresentação ppt, de 2016.

"Improving infrastructure is top priority" in The Japan Times, 2 de maio de 2014.

Timorese Reef Check, Relatório de 2008.

World Database on Protected Areas (WDPA), http://www.protectedplanet.net/country/TL, consultado a 20 de maio de 2016. 